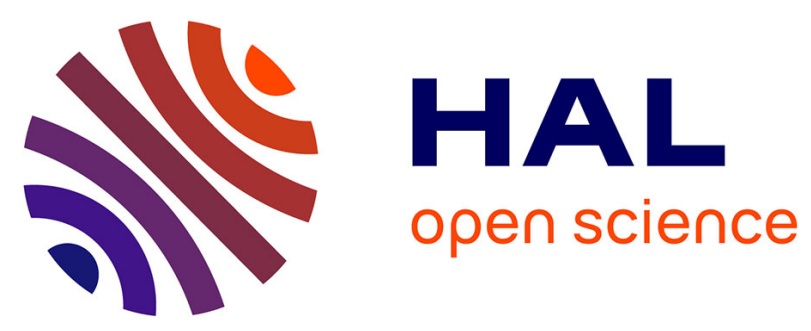

\title{
Phase Noise Measurements of High Overtone Bulk Acoustic Wave Resonators
}

Etienne Vaillant, Guillaume Combe, Valérie Petrini, Gilles Martin, Joël Imbaud, Thomas Baron, Fabrice Sthal, François Xavier Esnault, Gilles Cibiel, Jean-Marc Lesage

\section{To cite this version:}

Etienne Vaillant, Guillaume Combe, Valérie Petrini, Gilles Martin, Joël Imbaud, et al.. Phase Noise Measurements of High Overtone Bulk Acoustic Wave Resonators. International Frequency Control Symposium, May 2016, New Orleans, United States. hal-03053114

\section{HAL Id: hal-03053114 https://hal.science/hal-03053114}

Submitted on 10 Dec 2020

HAL is a multi-disciplinary open access archive for the deposit and dissemination of scientific research documents, whether they are published or not. The documents may come from teaching and research institutions in France or abroad, or from public or private research centers.
L'archive ouverte pluridisciplinaire HAL, est destinée au dépôt et à la diffusion de documents scientifiques de niveau recherche, publiés ou non, émanant des établissements d'enseignement et de recherche français ou étrangers, des laboratoires publics ou privés. 


\section{Phase Noise Measurements of High Overtone Bulk Acoustic Wave Resonators}

\author{
E. Vaillant, G. Combe, V. Petrini, G. Martin, \\ J. Imbaud, T. Baron, F. Sthal \\ FEMTO-ST Institute \\ UFC, CNRS, ENSMM, UTBM, UBFC \\ Besançon, France \\ thomas.baron@femto-st.fr
}

\begin{abstract}
In this paper, a passive measurement system is used to explore the phase noise of high overtone bulk acoustic wave resonators. The chosen overtone is around $373 \mathrm{MHz}$ and the temperature coefficient of frequency at room temperature is $4 \mathrm{ppm} / \mathrm{K}$. The $1 / f$ noise is clearly shown and a flicker floor of about $\sigma_{y_{-} \text {floor }}=1.5 \times 10^{-11}$ is demonstrated.
\end{abstract}

Keywords—1/f noise; resonator; HBAR; MEMS; phase noise; carrier suppression.

\section{INTRODUCTION}

The FEMTO-ST Institute, Besancon, France and the French space agency (CNES), Toulouse, France investigate the origins of noise in bulk acoustic wave resonators for several years [1]. Numerous micro-resonators dedicated to time bases are now developed by many laboratories [2-7]. They used collective process and clean room microtechnologies. Many resonating devices can be used to stabilize oscillators and their frequency stability is a condition for a low generated noise. The oscillator is often directly associated with the resonator. Then the contribution in term of noise of the resonator compared with the electronic circuit noise of the oscillator is not well known. Thus, these MEMS technologies could be perturbed by the inherent noise of the resonator which limits performances. Phase noise is one of the most generic methods of expressing frequency instability.

In this paper, we propose to measure the inherent noise of HBAR resonators without the associated oscillator. High overtone bulk acoustic wave resonators (HBAR) are based on a thinned $\mathrm{LiNbO}_{3}$ piezoelectric layer transferred on a $\mathrm{LiTaO}_{3}$ substrate. Previous paper describes this kind of resonator and give some performances in term of $Q . f$ product and behavior with temperature [8].

A first measurement has been done with a digital crosscorrelation phase modulation noise measurement system: Symmetricom 5125A. This system is not enough to measure the HBAR because of its noise floor. Around $400 \mathrm{MHz}$, the datasheet of the device gives $-110 \mathrm{dBc} / \mathrm{Hz}$ at $1 \mathrm{~Hz}$ offset from the carrier. This result implies that the phase noise of the HBAR can't be seen if it is under $-110 \mathrm{dBc} / \mathrm{Hz}$ at $1 \mathrm{~Hz}$ offset.

First a characterization of HBAR is done to measure the quality factor at chosen frequency. Then, the phase noise

\author{
F-X. Esnault*, G. Cibiel* \\ J-M. Lesage ${ }^{\#}$ \\ *Microwave and Time-Frequency Department, CNES, \\ Toulouse, France \\ "DGA - Information Superiority, \\ DGA, French MoD, \\ Bruz, France
}

measurement has been done with a passive method using carrier suppression technique [9], at $373 \mathrm{MHz}$. This method provides a better noise floor than the $5125 \mathrm{~A}$ at $1 \mathrm{~Hz}$ offset from the carrier. A frequency synthesizer has been used as driving source of the resonator.

\section{RESONATOR CHARACTERISTICS AND CONDITIONING}

\section{A. HBAR principle}

HBARs combine the outstanding properties of the strong coupling coefficient of the deposited piezoelectric thin film and of the high intrinsic quality substrates. The piezoelectric film and the two electrodes on opposite sides are used as a transducer whereas the acoustic energy is mainly trapped in the substrate, Fig. 1. Resonance frequencies correspond to integer numbers of half wavelengths in the entire thickness. Unlike Film Bulk Acoustic Resonator (FBAR) and Solidly Mounted Resonator $(S M R)$ in which only odd overtones exist, both odd and even overtones are compatible with resonance modes satisfying the electrical and mechanical boundary conditions. For more details, the reader can look at [10].

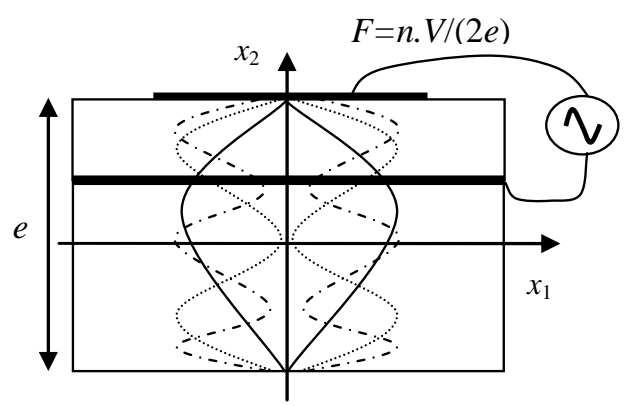

Fig. 1. Principle of a $H B A R$, showing possible harmonics distribution within the stack.

\section{B. HBAR features}

For the experimentation, we use HBAR constituted by $\mathrm{LiNbO}_{3}(\mathrm{YXl}) / 163$ piezoelectric layer on $\mathrm{LiTaO}_{3} \mathrm{Z}$-cut substrate. $\mathrm{LiTaO}_{3}$ material presents low acoustic attenuation. To facilitate the measurement, we use low frequency overtone around $373 \mathrm{MHz}$. The $Q . f$ product is around $8.2 \times 10^{12} \mathrm{~Hz}$, as shown with the result presented in Fig. 2. 


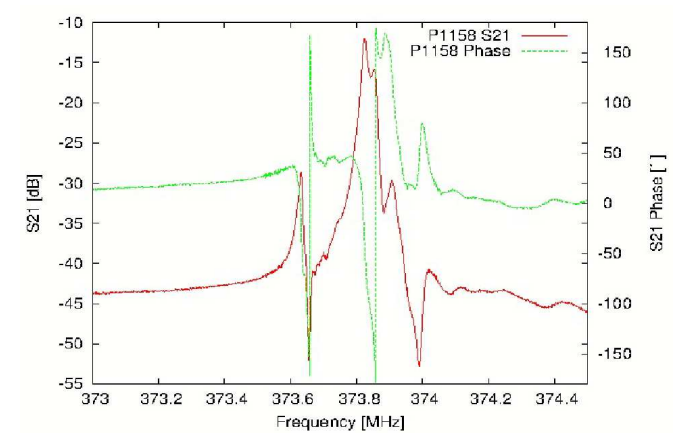

Fig. 2. Electrical response of $H B A R$ with $\mathrm{LiNbO}_{3} \quad(\mathrm{YXI}) / 163^{\circ}$ as piezoelectric layer and $\mathrm{LiTaO}_{3}(\mathrm{YXl}) / 90^{\circ}$ as substrate. This overtone exhibits Q.f product around $8.2 \times 10^{12} \mathrm{~Hz}$.

HBAR is directly wire bonded on a PCB with two SMA connectors. Encapsulation of the whole PCB isolates the HBAR, as shown in Fig. 3. The temperature coefficient of frequency at room temperature is $4 \mathrm{ppm} / \mathrm{K}$ for the overtone at $373 \mathrm{MHz}$.

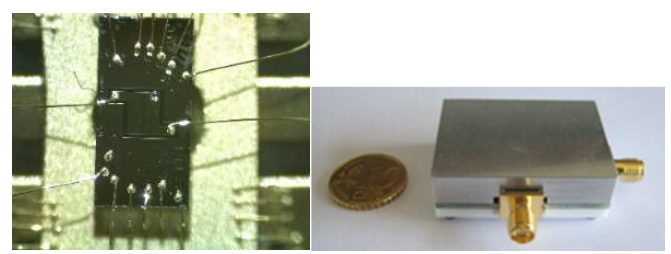

Fig. 3. Photography of packaged HBAR on PCB. On the left, photography of HBAR on ceramic with wire bonding. On the right, package of the HBAR.

The $373 \mathrm{MHz}$ frequency has been chosen considering the quality factor and the insertion loss, shown in Fig. 4. The minimum of insertion loss corresponds to a $Q$ factor around 25,000. The $Q$ factor can also be determined from the $S_{12}$ parameters, shown in Fig. 5. The slope of the phase at the resonant frequency $f_{\text {res }}$ leads to the Leeson frequency $f_{L}$, according to (1):

$$
f_{L}=\frac{1}{\frac{\Delta \emptyset}{\Delta f_{ \pm 1^{\circ}}}}
$$

The Q factor is then calculated using $Q_{L}=\frac{f_{r e s}}{2 \cdot f_{L}}$.

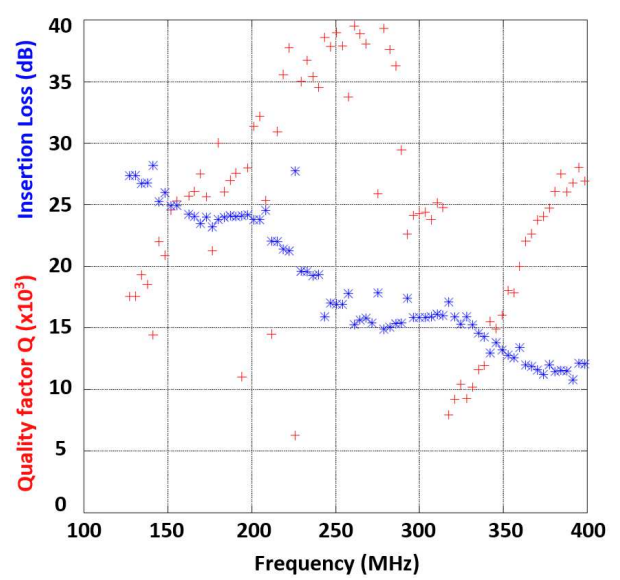

Fig. 4. Insertion Loss and Quality Factor versus Frequency.

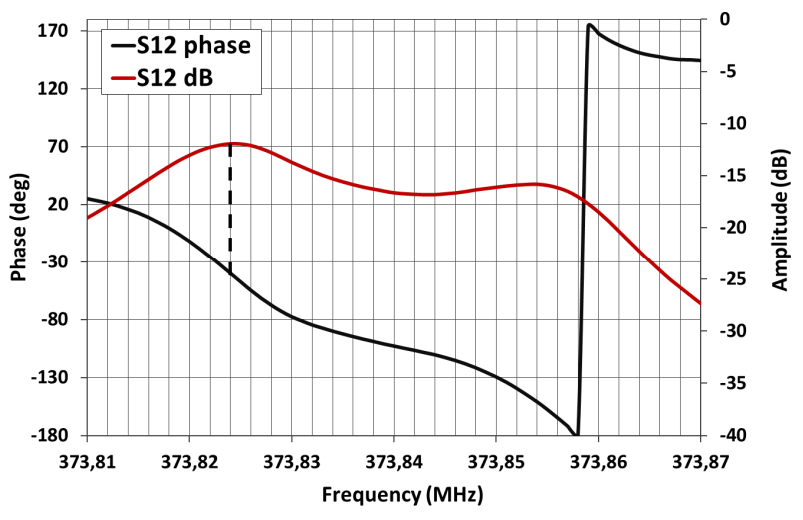

Fig. 5. $S_{12}$ parameters of the tested HBAR around $373 \mathrm{MHz}$.

Moreover, $\mathrm{LiTaO}_{3} \mathrm{Z}$-cut is a cut orientation exhibiting a near zero frequency drift [11]. Electronic dedicated to heat the resonator have been implemented at 8 different temperatures. A turn-over point is found around $55^{\circ} \mathrm{C}$. Fig. 6 shows the impact of temperature variations. The main results are summarized in Table I.

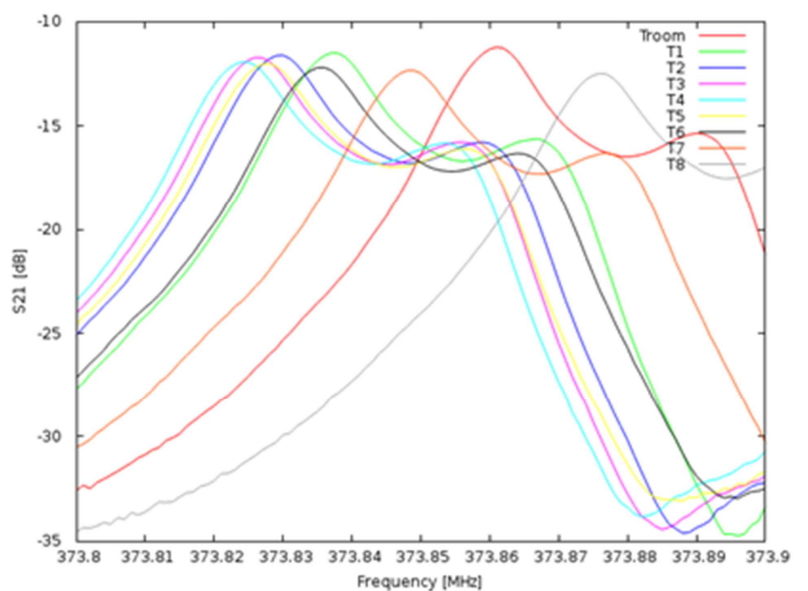

Fig. 6. Frequency evolution versus temperature. $\mathrm{T}_{0}=25^{\circ} \mathrm{C} ; \mathrm{T}_{1}=38.6^{\circ} \mathrm{C}$; $\mathrm{T}_{2}=46.4^{\circ} \mathrm{C} ; \quad \mathrm{T}_{3}=51.7^{\circ} \mathrm{C} ; \quad \mathrm{T}_{4}=61.9^{\circ} \mathrm{C} ; \quad \mathrm{T}_{5}=69.7^{\circ} \mathrm{C} ; \quad \mathrm{T}_{6}=77.8^{\circ} \mathrm{C} ; \quad \mathrm{T}_{7}=85.3^{\circ} \mathrm{C} ;$ $\mathrm{T}_{8}=96^{\circ} \mathrm{C}$.

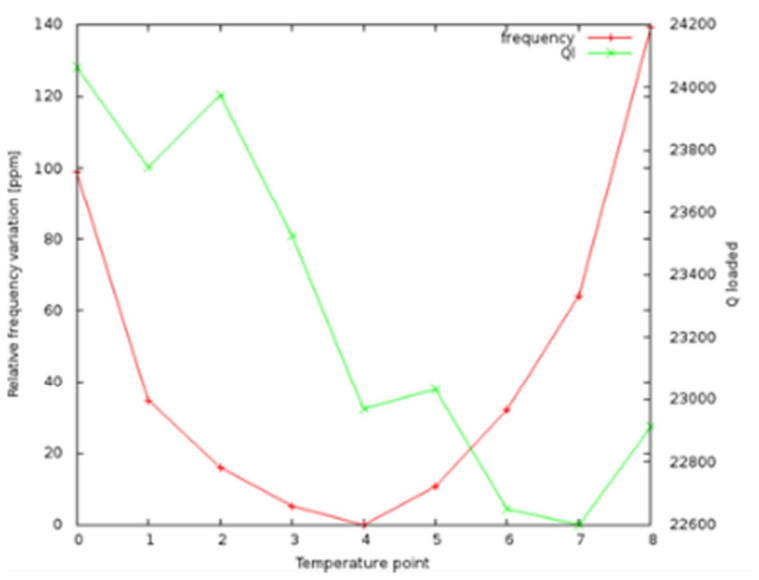

Fig. 7. Relative frequency variation and $\mathrm{Q}$ loaded versus temperature of overtone around $373 \mathrm{MHz}$ of $H B A R . \mathrm{T}_{0}=25^{\circ} \mathrm{C} ; \mathrm{T}_{1}=38.6^{\circ} \mathrm{C} ; \mathrm{T}_{2}=46.4^{\circ} \mathrm{C}$; $\mathrm{T}_{3}=51.7^{\circ} \mathrm{C} ; \mathrm{T}_{4}=61.9^{\circ} \mathrm{C} ; \mathrm{T}_{5}=69.7^{\circ} \mathrm{C} ; \mathrm{T}_{6}=77.8^{\circ} \mathrm{C} ; \mathrm{T}_{7}=85.3^{\circ} \mathrm{C} ; \mathrm{T}_{8}=96^{\circ} \mathrm{C}$. 
It clearly appears in Fig. 7 that the most suitable temperature to work with is $\mathrm{T}_{4}=61.9{ }^{\circ} \mathrm{C}$. Considering this temperature, the driving source of the phase noise measurement system has been adjusted to the appropriate frequency.

TABLE I. FREQUENCY VARIATION OF THE HBAR AT DIFFERENT TEMPERATURES

\begin{tabular}{|c|c|c|c|c|}
\hline $\boldsymbol{T}^{\circ} \boldsymbol{C}$ & $\begin{array}{c}\text { Freq. } \\
(\mathbf{M H z})\end{array}$ & $\begin{array}{c}\boldsymbol{S}_{12} \text { max } \\
(\boldsymbol{d B})\end{array}$ & $\begin{array}{c}\text { Freq. } \\
\text { variation } \\
(\boldsymbol{p p m} / \mathbf{K})\end{array}$ & Qfactor \\
\hline $\mathbf{2 5}$ & 373.860 & -11 & $\mathbf{3 . 8}$ & 24100 \\
\hline $\mathbf{6 1 . 9}$ & 373.824 & -12 & $\mathbf{0 . 3}$ & 23000 \\
\hline $\mathbf{9 6}$ & 373.875 & -12.5 & $\mathbf{6 . 8}$ & 22900 \\
\hline
\end{tabular}

\section{PHASE NOISE MEASUREMENTS}

The phase noise measurement of the HBAR resonator has been done using a carrier suppression system. The principle of this method is to reduce the noise from the source leaving the noise coming from the measured resonator. A block diagram of the principle is shown in Fig. 7. The input power of the system comes from a synthesizer referenced to an ultra-stable hydrogen maser. The carrier signal of the driving source is split into two equal parts to drive the two arms of the system, on one of which the Device Under Test (DUT) is set-up. On the other one an attenuator and a phase shifter are installed in order to equilibrate the system. The carrier of the driving source is then canceled when the two signals are combined $180^{\circ}$ out of phase.

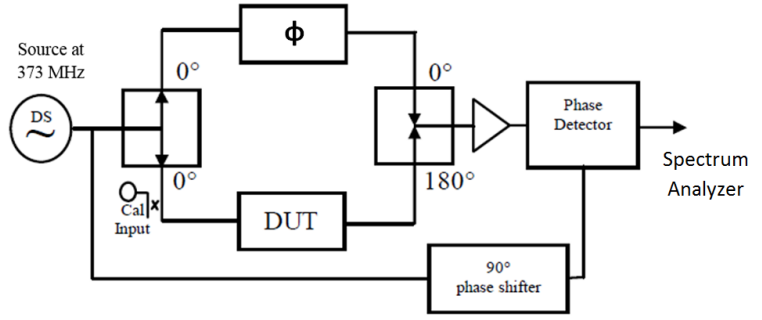

Fig. 8. Block diagrame of the carrier suppression principle

When the carrier suppression is achieved (less than $-75 \mathrm{dBc}$ is enough), the resulting signal only made up of the noise coming from the resonator, is strongly amplified and mixed with the source signal to be shifted down to the low frequency domain and processed by the spectrum analyzer. Calibration of the measurement system is obtained by injecting a known amount of phase noise (simulated by a sideband) on the arm containing the DUT. The measurement is corrected using a calibration factor determined from the sideband.

\section{RESULTS}

A measurement of the single-sideband Power Spectral Density (PSD) of phase fluctuation, $\mathscr{L}(f)$ of the HBAR at $f_{\text {res }}=373 \mathrm{MHz}$, is shown in Fig. 98. The drive level power dissipated by the resonators is about $70 \mu \mathrm{W}$. No thermal stabilization is done, and the measurement is obtained at room temperature.

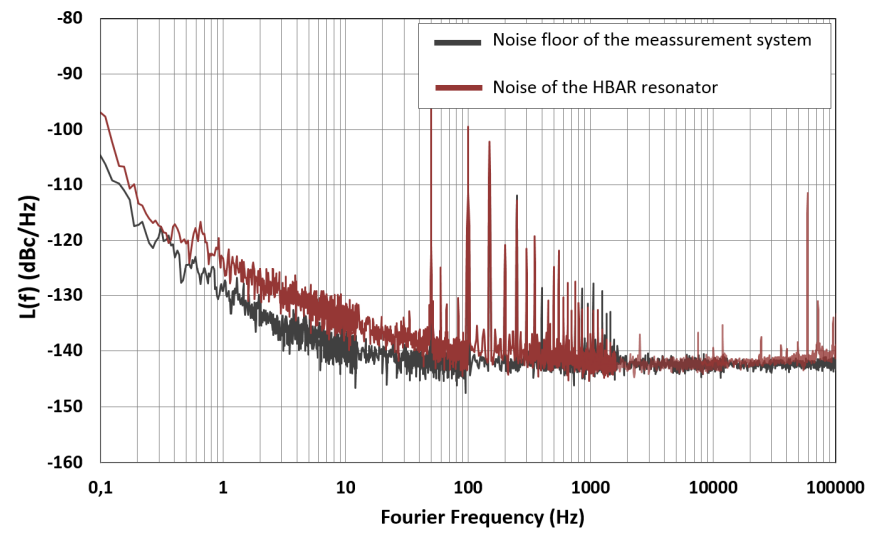

Fig. 9. Spectrum of phase noise for the resonator at $373 \mathrm{MHz}$, with a driving power equal to $70 \mu \mathrm{W}$. No thermal stabilization was used during the measurement.

We can visualize the $1 / f$ noise of the resonator between 0.5 and $100 \mathrm{~Hz}$ that is expected but never shown before. The HBAR resonator shows a phase noise of $\mathcal{L}(f)=-125 \mathrm{dBc} / \mathrm{Hz}$ at $1 \mathrm{~Hz}$ offset from the carrier.

In this case, the loaded $Q$, determined before the phase noise measurement, is about 24.000 , then the cut-off frequency $f_{L}$ should be around $8.5 \mathrm{kHz}$. This part of the slope is not visible because it is under the noise floor of the system. Phase noise measurements at different driving power will permit to visualize this cut-off frequency.

Considering the $1 / f$ noise slope and the noise value obtained at $1 \mathrm{~Hz}$ in Fig. 8, we can give the Allan standard deviation $\sigma_{y_{-} \text {floor }}$ of an oscillator containing the test resonator in which the only source of flicker frequency noise is the test resonator [9].

$$
\sigma_{y_{-} \text {floor }}=\sqrt{2 \cdot \ln 2 \cdot S_{y}(1 \mathrm{~Hz})}
$$

With $S_{y}(1 \mathrm{~Hz})$, the PSD of the relative frequency fluctuations at $1 \mathrm{~Hz}$. In Fig. 9, $\mathscr{L}(1 \mathrm{~Hz})$ is around $-125 \mathrm{dBc} / \mathrm{Hz}$, then $S_{\varphi}(1 \mathrm{~Hz})$ is $-122 \mathrm{dBrad}^{2} / \mathrm{Hz}$. The relationship between $S_{\varphi}$ and $S_{y}$ is given by:

$$
S_{y}(1 H z) \approx \frac{f_{L}^{2}}{f_{r e s}^{2}} S_{\varphi}(1 H z)
$$

This gives a flicker floor of about $\sigma_{y_{f} \text { floor }}=1.5 \times 10^{-11}$. This first result shows a short-term stability that is in the range between usual Temperature Compensated Crystal Oscillators (TCXO) and Oven Controlled SAW Oscillators (OCSO). Knowing HBAR behavior in term of $Q$ factor [8] and considering that the higher modes present better $Q . f$ product than the Q.f product of $8.2 \times 10^{12} \mathrm{~Hz}$ of the overtone described in this paper, improvement of bench characterization of the phase noise at higher frequency should give us very promising results in the future.

\section{CONCLUSION}

In this paper the phase noise of a HBAR resonator has been explored using a passive measurement system. The $1 / f$ noise is clearly shown. A flicker floor of about $\sigma_{y}$ floor $=1.5 \times 10^{-11}$ shows a short-term stability that is in the range between usual TCXO and OCSO. 
Furthermore, in our case, a more precise stabilization of the temperature of the HBAR should improve the phase noise at $0.1 \mathrm{~Hz}$. Measurement under this condition will be done.

The motivation of this work is to improve the knowledge of the HBAR resonators to address oscillator applications. An oscillator will be achieved, which will allow its comparison with what can be expected in view of the measured phase noise.

\section{ACKNOWLEDGMENT}

Authors thank the "Région Franche-Comté" and CNES, for the founding support, the Oscillator-IMP platform (PIA ANR) and the other members of the discussion group of "MEMS Noise" for their helpful discussions (L. Arapan, B. Dulmet, V. Giordano, S. Galliou and E. Rubiola). This work was partly supported by the french RENATECH network and its FEMTOST technological facility.

\section{REFERENCES}

[1] F. Sthal, M. Devel, J. Imbaud, R. Bourquin, A. Bakir, C. Vuillemin, G. Santunu, P. Abbe, D. Vernier, G. Cibiel, "1/f noise of quartz resonators: Measurements, modelization and comparison studies", Proc. IEEE Joint UFFC, EFTF and PFM Symp., Denver, Colorado, 12-16 April, pp. 158$161,2015$.

[2] T. L. Naing, T. O. Rocheleau, E. Alon, C. Nguyen, A "78- $\mu$ W GSM Phase Noise-Compliant Pierce Oscillator Referenced to a 61-MHz Wine-Glass Disk Resonator", in Proc. IEEE Int. Freq. Contr. Symp., pp. 562-565, 2013

[3] G. Piazza, A. Tazzoli, N. Miller, J. Segovia, C. Cassella, J. Koo, B. Otis, K. McNaul, B. Gibson, K. Turner, T. Palmer, "Dynamics of Microscale Thin Film AlN Piezoelectric Resonators Enables Low Phase Noise UHF
Frequency Sources", in Proc. IEEE Int. Freq. Contr. Symp., pp. 555558,2013

[4] R.G. Nagele, H.P. Moyer, D. J. Kirby, Y. Yoon, R. L. Kubena, R. J. Joyce, P. D. Brewer, D. T. Chang, "A 995MHz Fundamental Nonlinear Quartz MEMS Oscillator”, in Proc. IEEE Int. Freq. Contr. Symp., pp. 566-570, 2013.

[5] M.E. Ivan, B. Dulmet, G. Martin, P. Abbe, L. Robert, S. Ballandras, "New electrostatically-excited single crystal silicon resonator vibrating in a Thickness-Extensional mode", in Proc. IEEE Int. Freq. Contr. Symp., pp. 743-748, 2012.

[6] T. Barron, D. Gachon, G. Martin, S. Alzuaga, D. Hermelin, J.P. Romand, S. Ballandras, "Temperature Compensated Radio-Frequency Harmonic Bulk Acoustic Resonators", in Proc. IEEE Int. Freq. Contr. Symp., pp. 652-655, 2012.

[7] P. Varshney, B. S. Panwar, P. Rathore, S. Balandras, B. François, G. Martin, J. M. Friedt, T. Retornaz, "Theoretical and experimental analysis of high Q SAW resonator transient response in a wireless sensor interrogation application", in Proc. IEEE Int. Freq. Contr. Symp., pp. 451-456, 2012.

[8] B. Thomas, M. Gilles, C. Nicolas, P. Valérie, C. Guillaume, H. Fabien, B. Florent, R. David, C. Luc, R. Alexandre, L. Pierre-patrick, L. JeanMarc, and B. Sylvain, "High-Q and low TCF HBAR based on LiTaO3 substrate," Freq. Control Symp., pp. 1-4, 2014.

[9] F. Sthal, J. Imbaud, X. Vacheret, P. Salzenstein, G. Cibiel, S. Galliou, "Computation method for the short-term stability of quartz crystal resonators obtained from passive phase noise measures", IEEE Trans. on Ultrason., Ferroelect. and Freq. Contr., vol. 60, no. 7, July, pp. 15301532, 2013.

[10] T. Baron, E. Lebrasseur, F. Bassignot, G. Martin, V. Pétrini, and S. Ballandras, Chapter 13 High-Overtone Bulk Acoustic Resonator. Modeling And Measurement Methods For Acoustic Waves And For Acoustic Microdevices. 2013.

[11] S. V. Krishnaswamy, B. R. McAvoy, J. H. L. Salvo, and R. A. Moore, "Temperature Frequency Characteristics of Selected high Q acoustic Materials," Ultrason. Symp., pp. 421-423, 1984. 